\title{
Researchers may be part of the problem in predatory publishing
}

\author{
Cite as: CMAJ 2017 October 23;189:E1324-5. doi: 10.1503/cmaj.109-5507
}

Posted on cmajnews.com on Oct. 5, 2017.

$$
\text { t }
$$

t may start with the promise of speedy publication at a price that's too good to be true, or perhaps a desperate search after receiving a rejection letter. Some researchers don't see the red flags, blinded by pressure to publish. Others may choose to look the other way in order to pad their resumes. But in the end, the problem of predatory journals goes beyond publisher and prey.

Academic policies that reward researchers for publishing quantity over quality are driving the market for opportunistic journals that will print anything for a price, says Jeffrey Beall, a librarian at the University of Colorado Denver. "This gap allows people to easily use predatory journals to up their publication counts."

Beall once catalogued thousands of suspected predatory journals on a blog but shuttered the site in January due to what a business partner described as "threats and politics." A website that defames Beall has since appeared at a nearly identical address.

"Many researchers who purposefully use predatory journals become the journals' biggest defenders, and they attack anyone who questions the quality of their pet journals," says Beall.

Smart people are still "genuinely tricked," but not everyone who publishes with a predator is prey, he explains. Some researchers just want to get manuscripts off their desks as quickly as possible. Others use the journals to legitimize activist science and conspiracy theories.

Universities affiliated with these researchers have to start holding them accountable, Beall argues. "Tenure committees and deans should refuse to grant credit for publication outside of bona fide journals, books, [and] conference proceedings."

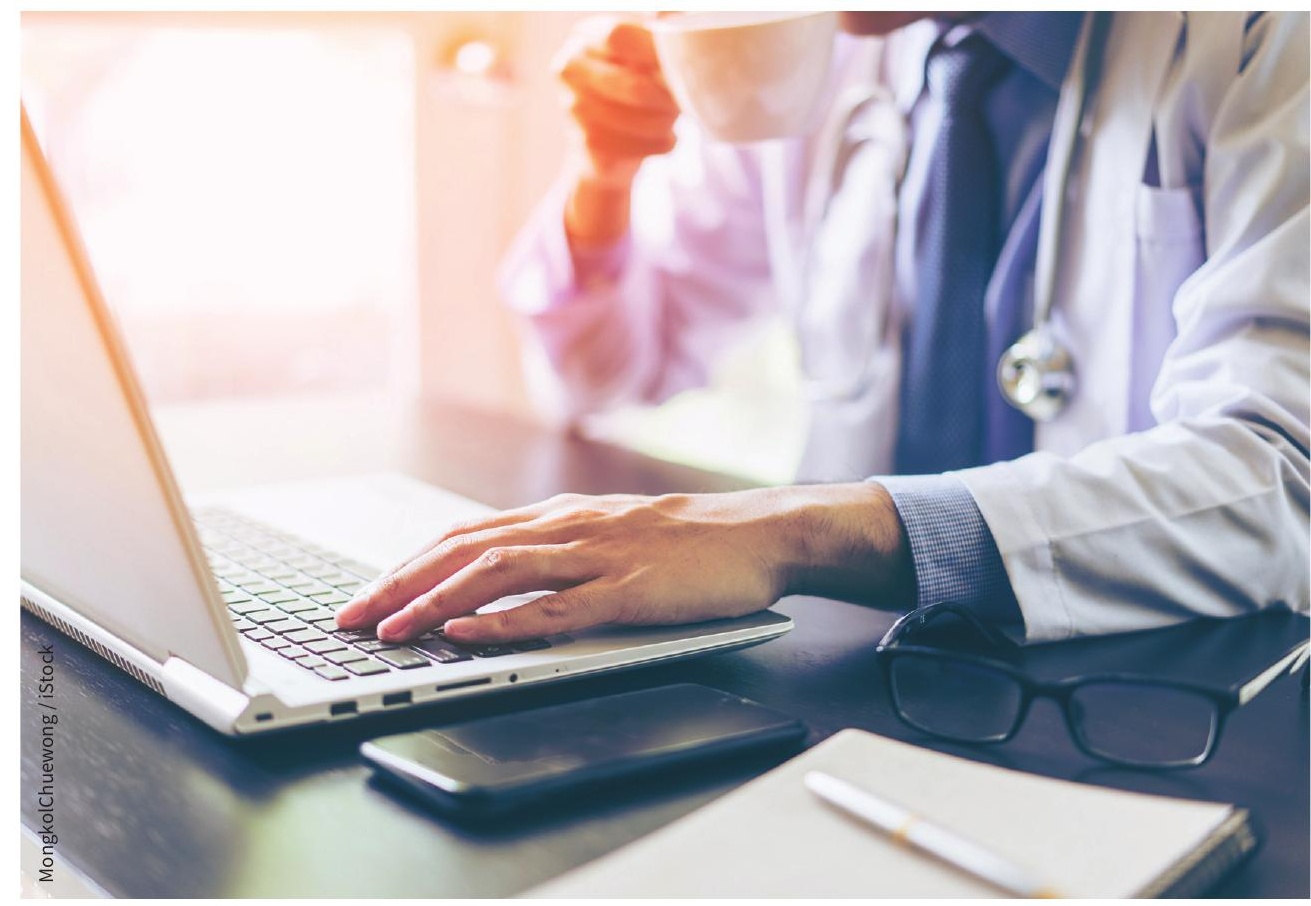

Institutions and funders have turned a blind eye to predatory journals for too long, say scholarly publishing experts.

The scholarly publishing industry also needs to "clean up its act and regulate itself," he says. This includes creating policies for eliminating "junk" from scholarly indexes and databases. "The industry has been mostly negligent in this, so the problem grows and worsens."

A recent survey of nearly 2000 articles in more than 200 suspected predatory journals found that more than half of the contributing authors came from upper-middle and high income countries. The sample included papers linked to top institutions and major public funders, including the United States National Institutes of Health and the Canadian Institutes of Health Research.

These findings indicate a truly global threat to scholarly integrity, says coauthor
Dr. Manoj Lalu, an associate scientist and anesthesiologist at The Ottawa Hospital. "Folks are largely being duped and they don't recognize the difference between a predatory and legitimate journal."

Lalu and his colleagues are calling on institutions and funders to educate researchers about predatory publishing, and create the right mix of incentives and deterrents to ensure the lesson sticks.

This should include issuing explicit warnings against dodgy publishers, and conducting random audits of publications by faculty members, research staff or grantees. Institutions could also follow the Ottawa Hospital Research Institute's lead by hiring publications officers to help scientists determine where to publish and 
what to do if they mistakenly submit to a predatory journal.

These suggestions are "all things that are worth considering," says Susan Zimmerman, executive director of Canada's Secretariat on Responsible Conduct of Research. However, she questions the value of disincentives. "If people innocently publish in journals that they don't realize are predatory, are you suggesting they should be penalized for that?"

"White lists" of reputable publications may be more useful than "black lists," which quickly become dated, Zimmerman says. Compiling any list is compli- cated because "it's not always easy to clarify what is a predatory journal."

Academic librarians used to help researchers sort the wheat from the chaff, says Susan Brown, president of the Canadian Society for Digital Humanities. Now, "their contact with researchers is often sporadic."

Scholarly publishing is changing at a bewildering rate, she says. The resources required to investigate journals and the "liability concerns" involved in exposing suspected predators pose additional challenges.

And what about substandard publications in legitimate journals? Quality issues aren't limited to predators, says Vincent Larivière, Canada Research Chair of the Transformation of Scholarly Communication at Université de Montréal. "We also observe that scientific misconduct is more likely to occur in high-impact journals."

It may be time to rethink for-profit publishing as the status quo, he says. "Predatory publishers are not the only predators in the system."

\section{Lauren Vogel, CMAJ}

Part two of a two-part series. Part one: Rich nations are feeding research predators 